\title{
Teaching cases and declinations without Syntax a cross-language method
}

Teodora Onutz 


\title{
Teaching cases and declinations without Syntax a cross-language method
}

\author{
Teodora Onutz ${ }^{\mathrm{a}^{*}}$ \\ ${ }^{a}$ Doctoral School "Educational, Reflection, Development", Babeş-Bolyai University, 7 Sindicatelor Street, 400029, Cluj-Napoca, Romania
}

*Corresponding author: onutzt@yahoo.com

\section{Abstract}

Keywords:

declination; syntax; cases; machine translation; language classification; language teaching.
Most Indo-European languages have had or still have a case system and declinations that influence how connections between words and ideas are made. They have followed several stages of development since the age of the common IndoEuropean language and have gotten more complex in structure or have lost most traces of said declinations. IndoEuropean languages today can be classified according to what type of declinations they have and how many cases. This article offers a classification of the languages according to that aspect, with the purpose of enabling the teaching/ learning of this part of grammar based on the similarities or differences between the native language and the target language. By identifying the stage of the native language based on the existing declinations, one can see what is needed to understand the case system of the target language, without needing to know syntax. It applies to Indo-European languages only, but it can be extended to encompass any other language that has declinations.

\section{Zusammenfasung}

\section{Schlüsselworte:}

Deklination; Syntax;

Fälle;

Maschinenübersetzung;

Sprachklassifizierung;

Sprache lehren.
Die meisten indoeuropäischen Sprachen hatten oder haben ein Fallsystem und Deklinationen, die Einfluss darauf haben, wie Verbindungen zwischen Wörtern und Ideen hergestellt werden. Sie haben seit dem Zeitalter der gemeinsamen indogermanischen Sprache mehrere Entwicklungsstadien durchlaufen und sind in ihrer Struktur komplexer geworden oder haben die meisten Spuren dieser Deklinationen verloren. Indogermanische Sprachen können heute nach der Art der Deklination und nach der Anzahl der Fälle klassifiziert werden. Dieser Artikel bietet eine Klassifizierung der Sprachen nach diesem Aspekt, um das Lehren / Lernen dieses Teils der Grammatik auf der Grundlage der Ähnlichkeiten oder Unterschiede zwischen der Muttersprache und der Zielsprache zu ermöglichen. Indem man die Stufe der Muttersprache anhand der vorhandenen Deklinationen identifiziert, kann man sehen, was zum Verständnis des Fallsystems der Zielsprache erforderlich ist, ohne die Syntax zu kennen. Sie gilt nur für indogermanische Sprachen, kann jedoch auf jede andere Sprache mit Deklinationen ausgeweitet werden.

\section{Introduction}

Cases and declinations are considered linguistic characteristics specific to Indo-European languages, along with word gender. This doesn't mean that all the languages of this family will have these characteristics, as some have lost them with time even if they did have them initially. Some elements, like cases, have been partially borrowed into other languages, like Semitic ones, sometime in Antiquity (Levin, 2002). Declinations are traditionally semantically associated with the roles of words in a sentence and are grouped according to that and the questions they answer to.

This can vary from language to language, a certain case can have some characteristics in Latin and others in Old Church Slavonic. That is why it has been hard to find a general pedagogical approach to them that works in most languages and only language specific syntactic solutions are used to teach them. The origin of declinations lies in the Common Indo-European language, which was reconstituted but left no written documents. Its features have been passed on, in one form or another, to all its descendants and in order to understand certain linguistic phenomena it is easier to look at ancient languages and reconstituted grammar.

"Indo-European is a declinate language. The declination is the change made to the shape of a word to show the grammatical connections that it establishes. The changes are sometimes made inside the word or at the beginning but most often at the end. It is possible that the endings of declinations to have initially had an independent meaning, that has now been forgotten. They 
were probably used like prepositions, auxiliaries and personal pronouns. In declinate languages like IndoEuropean, words are built from a root that in the early stages was probably used independently to express ideas. The roots are modified and become like stems that through declination form words. The whole process was initially one of composition through which specific endings were added one after the other to pronounceable forms through which a meaning was communicated." (Quiles \& Lopez-Menchero, 2011, p. 155).

The European languages of today that have inherited declinations in nouns are the Slavic languages, German, Romanian - the only one of the Romance languages, Greek, the Baltic languages and Albanian. Amongst the ancient languages that used them were Latin, Old Church Slavonic and Sanskrit. Latin passed them on to Romanian, Old Church Slavonic to all the Slavic languages, Sanskrit - to the Baltic languages. In modern languages we often find a simplified version of cases: with some cases disappearing completely, like the Latin Ablative case and Instrumental case, which were replaced in Antiquity, and others getting identical endings, like the Romanian Genitive-Dative case. The modern way of understanding how cases work is based mainly on syntax, which is used in the same manner in languages with or without declinations to analyse a sentence. But this presumes that the roles of each case are identical or similar in all languages, which isn't true and that the declination is made according to gender, which is a fact in German and Romanian but not in Slavic languages. In Common IndoEuropean and in ancient languages the declination was done following a different system, as found today in Slavic languages because they detached later from the Common Slavonic and are thus closer to their origin.

Common Indo-European had three genders and the declination was made according to phonetics and accent, not gender. In time, some genders were grouped in the same declination because they had become better defined themselves (Haudry, 1992). The main distinction was between animate and inanimate nouns, which is still found in Slavic languages today and could be observed in some stages of Latin, when differentiating amongst neutral nouns and others - neutral nouns do not alternate between the Nominative and Accusative case. (Clarckson, Horrocks, 2007 p. 106). The neutral gender was initially used to designate inanimate things and only living beings were give masculine or feminine characteristics. The idea of gender was not central in the declination of words, what mattered was phonetics and the distinction between animate and inanimate. Today, the teaching of the case system is done primarily through distinctions of gender, although many exceptions need to be also covered and the methodology used for one language cannot be extended to another.

\section{Languages according to their types of declinations}

In order to recover the concept of declination we must go back to its original shape and role and understand that meaning does not lie in the words themselves but in the connections between them. The declination is an ending that is added to a word to give it a new meaning and to connect it to another word, a phenomenon that existed before the appearance of genders. It is possible that in the early stages the declinations represented individual prepositions added to words. A declination can appear in nouns, pronouns, adjectives and numerals.

In the first stage there was no difference between animate and inanimate or gender, and words expressed pure concepts, so a declination showed the relation between ideas and was made only phonetically. Declinations appeared in pronouns as a rule firstly.

In the second stage there is a difference between animate and inanimate words, with new endings and the declination represents the relations between ideas, the distinction between being and object and is still done phonetically. Declinations appear in pronouns as a rule and maybe in a simplified version in nouns.

In the third stage there are masculine and feminine genders for animates and neutral for inanimate, with new endings and the declination shows the relation between ideas, the distinction being/ object, the gender of the word, it is done both phonetically and according to genders and is the most complex level. Declinations appear constantly in nouns, pronouns, adjectives and numerals in sophisticated forms.

In the fourth stage the distinction between animate and inanimate is gone, genders have gotten strict forms and have been extended to all words, no matter their nature and the declination shows the relations between ideas, the word's gender and is mostly done according to gender. Declinations can appear simplified in nouns, pronouns, adjectives and numerals. 
In the fifth stage there is no declination in nouns, only in pronouns, there is no animate - inanimate distinction and genders are well defined and extended to comprise all the words, the relations between ideas are made through prepositions and the order of the words in the sentence. Declinations only appear in pronouns.

In the sixth stage there is no declination in nouns, only in pronouns, there is no animate - inanimate distinction, there are no genders, the relations between ideas are made through prepositions and the order of the words in the sentence. Declinations only appear in pronouns.

The Indo-European languages of today that have cases and declinations fit into one of these stages, based on the distinctions they have in words. English is a stage six, French and Spanish are a stage five, Romanian and German a stage four, Slavic languages and Latin are a stage three, Norse languages a stage two.

The evolution suggested above follows the logic by which we got to concepts of genders and cases, but it is not necessarily chronological, and it doesn't mean that all the languages have passed through all the stages. Depending on their linguistic family or branch they might have skipped some or gone back to a previous stage.

\section{Teaching the case system}

Teaching a new language must consider the nature of the native one, namely, to consider if the native tongue has genders, animate and inanimate distinctions, declinations, phonetic rules and if it doesn't, then they must be slowly introduced as concepts. For example, a Romanian learning Russian moves from a stage four native language to a stage three language, so from the concepts of gender and phonetic rule to the idea of animate/ inanimate. But an English speaker learning Russian must go from a stage six language to a stage three language, for which he needs to become familiarized with the idea of phonetic rule, animate / inanimate distinctions, genders and declinations.

The way in which the relations are formed between nouns/ adjectives/ pronouns in a language is easier to understand and learn than verbal tenses, because it is only needed to add new forms for the same meanings while with verbs, a complete rethinking of time is needed. The stage of a language can show what characteristics certain parts will have but it doesn't help in understanding how cases and declinations work. For this, we look at the connections between the words that give meaning and how they are established.

The simplest structure is:

Idea - idea - idea $=$ word - word - word

In this way only simple meanings can be communicated, and the order of the words is important.

For more complex meaning we need:

Idea - connection - idea - connection - idea $=$ word - preposition - word - preposition - word

The connection can then be added directly to the idea:

Idea + connection - idea + connection - idea + connection $=$ word + declination - word + declination - word + declination

Or the most complex, the connection can be both added to the idea as used separately:

Idea + connection - connection - idea + connection - connection - idea + connection $=$ word + declination preposition - word + declination - preposition - idea + declination

The connections can be similar in meaning and used together, when a certain preposition requires a certain declination, or they can be completely independent in their roles.
Between ideas and words there can be a multitude of connections that create meaning: who does the action, to whom something belongs, whose part something is, etc. This would mean that for every new meaning created there is a new connection, either as a preposition or a 
declination but it wouldn't be very efficient as some connections are made more often than others. It is more practical to use one connection for many meanings, a main one and some secondary ones, which is grammatically called a case. The case can contain a single meaning, several meanings, a declination, no declinations and certain prepositions.

A preposition can be used to establish more meanings and can differentiate between them by using a different declination. In this situation the preposition is used for more cases, depending on the required meaning. As practical examples, English establishes connections mainly through prepositions and only possession through declination, Romanian establishes connections through prepositions and declinations, but the prepositions are used for only one declination and Russian establishes connections through prepositions, declinations and the prepositions can be used with multiple declinations. When there is no form of connecting the words, what matters is their order in the sentence.

Presenting the cases in a language and their syntactic analysis is not a universal way of understanding and explaining the declination of nouns and their purpose. A given case can have different meanings in different languages. What matters more is how the relations / connections between the words are established. This can be done as stated before through the order of the words, prepositions between words, different endings for words (declinations), prepositions and declinations. The meaning is established through the relations so they can be presented as a summary of meanings, prepositions, endings/ declinations and the meanings they create. Or they can be presented starting from the relations that we would like to establish and the ways they are done in every language.

As an example, let's take the so-called Prepositional case in Russian, which doesn't exist in non-Slavic languages. It contains two meanings: where something is found, using the prepositions in and to, and what is discussed, using the preposition about but the declination stays the same. The declination comes first, as it is an ending/ connection for multiple meanings, differentiated

$$
\begin{aligned}
& \text { Word/noun } \rightarrow \text { meaning } A \\
& \text { Word/ noun }+ \text { ending } 1 \rightarrow \text { meaning } B \\
& \text { Word/noun }+ \text { ending } 1+\text { preposition } X \rightarrow \text { meaning } C \\
& \text { Word/noun }+ \text { ending } 1+\text { preposition } Y \rightarrow \text { meaning } D
\end{aligned}
$$

by the preposition. For morphological and syntactical philological reasons, it was established that these connections form this case called X but they don't help with the intuitive understanding of its role. The name and possible correspondences with other languages are done based on the existence of a common meaning in the multitude of meanings but can make practical learning and understanding complicated as such a case doesn't exist in many other languages. The same case can be explained starting from the ending that is changed in the words, i.e. the declination, as this change can refer to two meanings: where something is or what is discussed. In order to decide which one to choose, we should look at the preposition before it, so no knowledge of syntax is needed.

The key to teaching and learning the cases and declinations lies not in the cases and declinations themselves but in understanding the relation between meaning and form, namely which form contains which meaning.

\section{Applications in other fields}

The non-syntactic structure of cases and declinations can be applied in the field of Natural Language Processing and Machine Translations as well and developed into a general algorithm than can afterwards be adapted to suit each language. It can also be used to create connections between languages that share this sort of linguistic phenomenon, namely most of the Indo-European languages of today and even some outside of this linguistic family, like Arabic. If there is a stemming mechanism developed in said language then it can be applied along with it, but it works as an independent process as well. The basic structure is simple and needs only a limited amount of data to work.

Starting from the declination/ ending, having a specific meaning when applied to a noun, then adding the prepositions to change said meaning. Because there is a limited number of endings, with a limited number of prepositions creating a limited number of meanings, there shouldn't be any overlapping or confusion between them. 
Example: house

Дом + - $а \rightarrow$ дома (of the house)

Дом $+-a+$ возле $\rightarrow$ возле дома (near the house)

Дом $+-a+$ из $\rightarrow$ из дома (from the house)

Дом $+-a+$ до $\rightarrow$ до дома (to the house)

*The equations above have been simplified for clarity. In reality, the construction of the language requires that the prepositions are placed before the noun.

For example (возле + Дом $+-a)$

Adding a different declination to the same parameters:

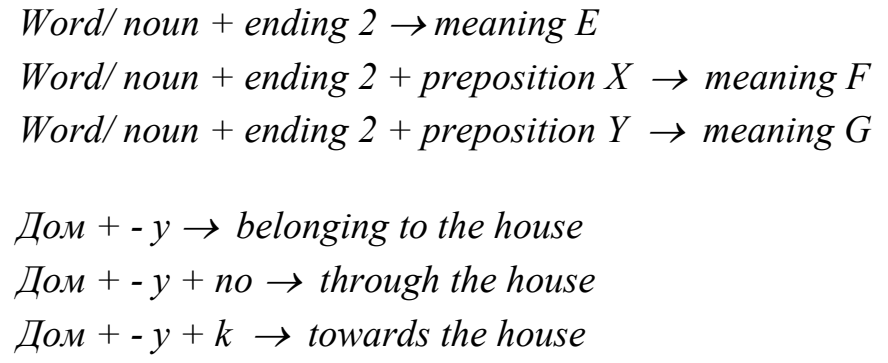

*The equations above have been simplified for clarity. In reality, the construction of the language requires that the prepositions are placed before the noun. For example $($ по + Дом $+-y)$

Then it can be connected to the declinations/ endings with the same meaning in another language:

Ending 1 in Russian $=$ ending 3 in Romanian $=$ ending 5 in English $=$ ending $\mathrm{x}$ in Arabic

a (е.g. дома in Russian) = ei (e.g. casei in Romanian) = 's (e.g. house’s in English) = i (e.g. بيت 1-bayti in Arabic)

No matter the word that is declinate, the meaning of the ending will stay the same so cross language analysis is possible without translation. Using a dictionary of base words, it is possible to isolate the noun independently of endings and prepositions. Further processing would then yield the ending and the preposition and give the idea of an abstract semantic meaning. Since this abstract meaning is language independent, running the process across disparate documents, gives implementation paths for cross-language meaning extraction, syntactic graph construction and cross language search without the requirement of full translation.

\section{Conclusions}

The method presented in this article has many practical uses. First of all, it is designed for teaching the role and usage of cases and declinations without needing to have knowledge of syntactic analysis, which can be applied to any language that has them. This makes it easier to teach languages to both children and adults by simplifying an otherwise complex linguistic phenomenon that can remain elusive to people outside of philology.

In addition, the same method can be applied in software development, helping with cross-language references and text disambiguation. It needs a data base of words: nouns, prepositions, endings and an algorithm for sentence structuring that can be adapted to different language groups. The data bases for the languages can then be interconnected and the need for translations in cross-reference search can be eliminated, thus time and energy are saved.

\section{Acknowledgements}

I would like to thank Richard Comish for his collaboration in developing the Machine Translations and Natural Language Processing application. 


\section{Authors note:}

Teodora Onutz, Ph.D. candidate, Education Sciences, Linguistics and Education, Language teacher, authorized translator and linguist, software development for Machine Translation, NLP, Machine Learning.

\section{References}

Levin, S. (2002). Semitic and Indo-European II Comparative morphology, syntax and phonetics. Amsterdam: John Benjamins Publishing Company.

Quiles, C., Lopez-Menchero, F. (2011). A grammar of Modern Indo-European. Sevilla: The Indo-European Language Association.

Haudry, J. (1992). L'Indo-européen. Paris: Presses Universitaires de France.

Clarckson, J., Horrocks, G. (2007). The Blackwell history of the Latin language. Oxford: Balackwell Publishing. 